\title{
Large-scale implementation of alcohol brief interventions in new settings in Scotland: a qualitative interview study of a national programme
}

Niamh Fitzgerald ${ }^{1,2^{*}}$, Lucy Platt ${ }^{3}$, Susie Heywood ${ }^{4}$ and Jim McCambridge ${ }^{3}$

\begin{abstract}
Background: This study aimed to explore experiences of implementation of alcohol brief interventions (ABIs) in settings outside of primary healthcare in the Scottish national programme. The focus of the study was on strategies and learning to support $A B I$ implementation in settings outside of primary healthcare in general, rather on issues specific to any single setting.

Methods: 14 semi-structured telephone interviews were conducted with senior implementation leaders in antenatal, accident and emergency and wider settings and audio-recorded. Interviews were analysed inductively.

Results: The process of achieving large-scale, routine implementation of ABI proved challenging for all involved across the settings. Interviewees reported their experiences and identified five main strategies as helpful for strategic implementation efforts in any setting: (1) Having a high-profile target for the number of ABls delivered in a specific time period with clarity about whose responsibility it was to implement the target; (2) Gaining support from senior staff from the start; (3) Adapting the intervention, using a pragmatic, collaborative approach, to fit with current practice; (4) Establishing practical and robust recording, monitoring and reporting systems for intervention delivery, prior to widespread implementation; and (5) Establishing close working relationships with frontline staff including flexible approaches to training and readily available support.
\end{abstract}

Conclusions: This qualitative study suggests that even with significant national support, funding and a specific delivery target, $\mathrm{ABI}$ implementation in new settings is not straightforward. Those responsible for planning similar initiatives should critically consider the relevance and value of the five implementation strategies identified.

Keywords: Alcohol, Brief intervention, Implementation, Brief advice, Target

\section{Background}

Alcohol brief interventions (ABIs) are heterogeneous interventions [1-4] that include 'short conversations aiming in a non-confrontational way to motivate individuals to think about and/or plan a change in their drinking behaviour in order to reduce their consumption and/or their risk of harm' [5]. ABIs have historically included the use of a screening questionnaire to explore an

\footnotetext{
* Correspondence: niamh.fitzgerald@stir.ac.uk

${ }^{1}$ Institute for Social Marketing, UK Centre for Tobacco and Alcohol Studies,

University of Stirling, Stirling FK9 4LA, Scotland, UK

${ }^{2}$ Institute for Health and Wellbeing Research, Robert Gordon University,

Riverside Campus, Aberdeen AB10 7GJ, UK

Full list of author information is available at the end of the article
}

individual's consumption level and risk of alcohol problems, and the provision of personalised feedback based on such screening [6].

Systematic reviews have concluded that ABI delivery in primary care has modest efficacy in reducing alcohol consumption in hazardous and harmful drinkers $[7,8]$. Evidence for efficacy in Accident and Emergency (A\&E) [9,10], general hospital [11], antenatal [12,13] and other settings including education, pharmacy and criminal justice [14-16] is less convincing. Furthermore the appropriateness, targeting and timing of screening for alcohol 
problems within various settings have been the subject of debate [17-21]. Notwithstanding this, implementation of ABIs has been recommended in the UK in a wide range of such settings (National Institute for Health and Care Excellence [22]; Scottish Government [23]). The Scottish Government national alcohol strategy states "we know brief interventions are effective in helping people to reduce their drinking, and as such their risk of alcohol related harm" in describing the national ABI programme, which prioritises implementation in $A \& E$, antenatal and primary care settings [24].

The implementation of interventions novel to practice in health and other settings is not straightforward $[25,26]$. One review identified four strategies for implementing ABIs in primary care, all aimed at practitioners, and concluded that material utilisation, screening, and brief intervention rates "increased with the intensity of the intervention effort, i.e. the amount of training and/or support provided" [27]. Another found that "adequate resources, training and the identification of those at risk without stereotyping" were the main facilitators of implementation but concluded that further research was needed outside of primary care [28]. Implementation issues in other settings are likely to both share similarities with primary care, and also be distinct.

From April 2008, a Scottish Government target [29] required the NHS as a whole to deliver a minimum number of ABIs in the three priority settings (primary care, A\&E, antenatal) and later a range of other 'wider' settings $[5,23]$. The national target was divided up into targets for each local health service ('health board') in Scotland, each of which was required to report regularly on implementation progress. The national initiative was well-resourced [24], encouraged local ownership of implementation $[29,30]$, focused on addressing risky drinking rather than alcohol dependence [30,31], emphasised professional education for nurses and doctors based on interactive skills teaching [31], and was delivered in the context of a high-profile government focus on 'changing Scotland's relationship with alcohol' [32]. Thus the programme reflected many of the 'lessons learned' from a similar project in Sweden [33], although both that and other national initiatives have met with modest implementation success [33-35]. In Scotland, ABIs were implemented extensively, with delivery of 470,540 ABIs reported over a six year period, exceeding the target of 332,692 [36]. No previous study has explicitly sought to investigate implementation strategies in this kind of target-driven programme for alcohol.

The aim of this study was to explore experiences of implementation of ABIs in settings outside of primary healthcare in the Scottish national programme in order to identify learning for implementation that may be relevant to any non-primary care setting.

\section{Methods}

\section{Sample}

All eleven local health services ('boards') in mainland Scotland (as well as three smaller island NHS boards) initiated programmes of ABI delivery outside of (and within) primary care in response to the national target. In each board, one or more senior practitioners were responsible for their board's performance in relation to the target ('implementation leaders') and for co-ordinating or overseeing related support or service development. We purposively identified experienced individuals from amongst this group, ensuring a range of both high and low performing health boards [37] and those with experience of a variety of settings were interviewed. Representatives of the three island health boards were not included as implementation in that context was judged likely to raise issues specific to their size and context. The final sample size was dictated by the resources available and the timescale for the study and is described in detail in Table 1.

\section{Data collection and ethics}

Scottish NHS ethics approval was not required for the study and ethical approval was granted by the Ethics Committee of London School of Hygiene and Tropical Medicine. Interviewees were fully informed about the study by email and followed up by telephone by NF. Full verbal consent was obtained by telephone and audio-recorded also by NF. Semi-structured telephone interviews (averaging $67 \mathrm{mi}$ nutes in duration) were conducted by NF between September and November 2013. Previous experience interviewing individuals in similar roles found telephone interviews to be preferable as they can be more easily cancelled with little or no notice should urgent clinical commitments arise. Interviewees were provided with a topic guide (Table 2) in advance, which was informed by both ABI-specific and generic implementation literature including the Consolidated Framework for Implementation Research (CFIR) [25]. During interviews, participants were encouraged to speak freely about their experiences, and questions were not asked verbatim of each participant. Particular attention was paid to drawing out participants' reflections on how best to approach ABI implementation in any new setting outside of primary care. Interviews were audio-recorded, notes simultaneously typed during the interviews and the recordings used afterwards to complete and correct the notes. All notes were subsequently checked for accuracy by interviewees at which point they also had the opportunity to elaborate or clarify any points. In some cases when quoting sections of the notes deemed controversial or sensitive by the participant or the authors, the interview code number is withheld, in order to protect the participant's anonymity and working relationships. 
Table 1 Profile of interviewees $(n=14)$, in line with COREQ and RATS guidelines $[62,63]$

\begin{tabular}{l} 
Job/profession \\
\hline 1. Alcohol \& Drug \\
Partnership (ADP) \\
Co-Ordinator
\end{tabular}
Role e.g. strategic only Health board area or clinical (patient-facing) \& strategic

2. Specialist ${ }^{\mathrm{b}}$ Nurse

Strategic

B
3. Specialist Nurse

4. Senior Medical Doctor ${ }^{\mathrm{C}}$ (A\&E)

5. Senior Medical Doctor (Public Health)

6. ADP Officer

7. Specialist Nurse

8. Specialist Nurse

9. Senior Medical Doctor (A\&E)

10. Senior Medical Doctor (Public Health)

11. Senior NHS Manage

12. ADP Co-Ordinato

13. Specialist Nurse

Clinical \& strategic

Strategic

Clinical \& strategic

Clinical \& strategic

Strategic

Strategic

Clinical \& strategic

Clinical \& strategic

Strategic

Strategic

Strategic

G

14. Specialist Nurse
Clinical \& strategic

\section{int}

interviewee responsible

for $A B I$ implementation?

Range of $A B I$ delivery performance

in the sample for each setting

A\&E

Antenatal

Wider'd settings

A\&E

Antenatal

Wider settings

A\&E

A\&E

A\&E

Antenatal

Wider settings

A\&E

Antenatal

Wider settings

A\&E

Antenatal

A\&E

A\&E

Antenatal

Wider settings

A\&E

Antenatal

Wider settings

A\&E

Antenatal

Wider settings

A\&E

Antenatal

Wider settings

Antenatal
For each of the 8 health boards for which

interviews were conducted, the \% of ABls

delivered across primary care, A\&E, antenata

and wider settings as a proportion of the

total delivered across all settings was available.

This was used to designate boards as high performing or low performing in each setting as follows: $\%$ of overall ABls delivered in the setting.

Low performing $=$ below or equal to median $\%$ of overall ABls delivered in the setting.

These are not indicated specifically for each health board area as it could enable identification of health boards, potentially compromising the anonymity of interviewees.
High performing $=$ above the median 
Table 1 Profile of interviewees $(n=14)$, in line with COREQ and RATS guidelines $[62,63]$ (Continued)

Totals

ADP: 3

Strategic: $8 \quad 8$ of 11 mainland

\section{A\&E: 12}

Antenatal: 10

A\&E: 4 low performing; 4 high performing

Specialist nurse: 6

Clinical \& strategic: 6

Wider settings: 8

Antenatal: 4 low performing; 4 high performing

Wider settings: 3 low performing; 5 high performing

4 (2 public health; 2 A\&E)

NHS Manager: 1

Duration of Involvement: Twelve interviewees had been involved in the ABI programme for over five years i.e. at least from the start of the national target, the others for two and three years.

Non-Participation: Of those sampled, one individual (a senior midwife) who had initially agreed to take part, failed to respond after several attempts to arrange the interview. No sampled individuals declined to take part.

Relationship Established: Prior to interview, five participants were well known, two less well-known and the others not known at all to the interviewer, who was at the time working as an independent researcher. ${ }^{\mathrm{a} A D P s}$ are local strategic multi-agency partnerships responsible for taking forward action to address alcohol and drug misuse.

${ }^{\mathrm{b}}$ Alcohol/addiction/substance misuse/mental health specialty.

c Consultant level.

dWider settings are other settings outside of primary care, including hospital wards, pharmacies, youth and community settings. 
Table 2 Summary of topic guide

\begin{tabular}{l} 
Questions from Topic Guide \\
(without prompts under each question) \\
\hline 1. How did you get involved with ABI implementation in X health \\
board? \\
2. Who else was involved in the initiative? How were they involved? \\
3. When and how were frontline staff involved in the initiative? \\
4. How was the delivery of ABI designed to work in this setting? \\
5. In your experience, what are the important differences \\
between trying to implement ABI in primary care, and \\
trying to do so in A\&E/antenatal care? \\
6. How important was the national target and related activities in \\
driving forward implementation? \\
7. How sustainable is the delivery of ABIs in your view? \\
8. To what extent was implementation influenced by contextual or \\
organisational factors? \\
9. From all that you've mentioned, what would you pick out as the key \\
lessons for others trying to implement ABI outside of primary care \\
settings?
\end{tabular}

\section{Analysis}

Analysis was conducted after data collection and familiarisation with checked notes and recordings. As many interviewees had experience of multiple settings and the research question was not specific to these settings, all interviews were analysed together. NF and $\mathrm{SH}$ coded segments of interview manually using a simple inductive approach as themes emerged from the interviews. They met to discuss codes and broader themes arising. A framework matrix [38] was used to chart the data, organising the emergent themes into categories including, where relevant, categories relating to the domains of the Consolidated Framework for Implementation Research (CFIR) [25]. The matrix enabled a holistic, descriptive overview of the entire data set to be taken, and for the data to be considered through a broader 'implementation science' lens. NF and SH used it to reflect on and refine the overarching themes that were relevant to the research question.

\section{Results}

Five main areas of focus consistently emerged in interviewees' reports of their experiences of and learning about ABI implementation. Each area is discussed in further detail below and includes interviewees' views on barriers and helpful strategies for implementation within each one with illustrative quotes. A summary of results is provided in Table 3. Although participants sometimes highlighted elements of culture specific to one setting as a barrier to implementation (e.g. the nature of care in an $A \& E$ department), there were few differences in the kinds of helpful strategies identified by interviewees to resolve those barriers. These are outlined below. There were no clear differences in strategies identified in high
Table 3 Summary of themes and codes

\begin{tabular}{|c|c|}
\hline Overarching Areas of Focus & Codes \\
\hline \multirow[t]{3}{*}{ (1) The national ABI target: } & $\begin{array}{l}\text { 1A: Priority for managers } \\
\text { and health boards }\end{array}$ \\
\hline & 1B: Responsibility for target \\
\hline & 1C: Pressure \& distortions \\
\hline \multirow[t]{3}{*}{ (2) Leadership for implementation: } & 2A: Senior staff support \\
\hline & $\begin{array}{l}\text { 2B: Implementation leader } \\
\text { status }\end{array}$ \\
\hline & $\begin{array}{l}\text { 2C: Acknowledging prior } \\
\text { effort. }\end{array}$ \\
\hline \multirow{3}{*}{$\begin{array}{l}\text { (3) Flexibility, collaboration and } \\
\text { pragmatism in intervention design: }\end{array}$} & 3A: Desirable versus possible \\
\hline & $\begin{array}{l}\text { 3B: Building on current } \\
\text { practice }\end{array}$ \\
\hline & $\begin{array}{l}\text { 3C: Monitoring and crediting } \\
\text { pre-existing delivery }\end{array}$ \\
\hline \multirow[t]{3}{*}{$\begin{array}{l}\text { (4) Recording, monitoring } \\
\text { and reporting: }\end{array}$} & $\begin{array}{l}\text { 4A: Early evidence \& feedback } \\
\text { important }\end{array}$ \\
\hline & 4B: Difficulty recording \\
\hline & 4C: Mandatory recording \\
\hline \multirow{3}{*}{$\begin{array}{l}\text { (5) Engaging and supporting } \\
\text { frontline staff: }\end{array}$} & 5A: Involving staff throughout \\
\hline & 5B: Training flexibility \\
\hline & $\begin{array}{l}\text { 5C: Specialist support both } \\
\text { helpful and unhelpful. }\end{array}$ \\
\hline
\end{tabular}

and low performing health boards in terms of ABI delivery [37]. In line with the research question, the focus here is on those strategies identified as helpful that were common across the settings. Interviewees who reported success in embedding implementation in a particular setting, tended to report that they had used the identified strategies from earlier in their implementation efforts. Many felt that preparation for implementation needed to start early, long before routine or widespread delivery of ABIs was expected. Such a period of preparation would have been helpful, in their view, to get recording and reporting systems in place, to prepare training materials and tailored delivery plans, and to get the support of senior staff and national professional bodies. All interviewees clearly described the challenging nature of $\mathrm{ABI}$ implementation.

\section{The national $\mathrm{ABI}$ target}

The target was mostly, but not universally, considered helpful in efforts to secure ABI implementation across all settings. Most felt that the target drew the attention and support of senior managers at health board level, which either started the process of implementation, or increased the priority of ongoing ABI work. Two health boards had made use of local targets since 2012/13 and felt confident that these would ensure continued implementation of ABIs, whether or not ABIs continued to be a focus nationally. 
The target was definitely important. Health boards take the target seriously. They are monitored on them.... at the highest level...it probably wouldn't have happened without it being a target.

Interview 3, Both setting

Many interviewees felt that there was a lack of clarity locally about whose responsibility it was to ensure that the target was met. This resulted in a lack of ownership: a sense that 'everyone thought that it was somebody else's target' (interview 2). Only a few health boards subdivided the board target into a specific target for each of the eligible settings: primary care, antenatal, accident and emergency (and later wider settings). As one interviewee put it, this meant that 'the lines of accountability were stretched' (interview 5). Some implementation leaders reported that the target was seen as theirs to deliver, rather than the responsibility of frontline staff in the setting. In addition, the funding provided to support delivery of the target was recognised as being crucial for supporting implementation, as it was used to pay for implementation leaders, training and the adaptation of IT systems (see below).

Some interviewees suggested that the pressure felt at all levels to meet the target had some unintended consequences. These included distortions in recording such that reported ABI figures were felt in some cases to be misleading, delivery of ABIs by staff employed on short-term contracts rather than routine delivery, and resistance from staff who felt 'coerced' (interview 6) into delivering something that was 'foisted upon them' (interview 1).

People get pressure fatigue and project fatigue...they have multiple demands and multiple targets to meet while also operating under financial constraints with less people to do the work. People get burnout and say 'I just can't. I just can't do any more' and it's really difficult to know how to overcome that.

Interview 1, Both settings

Perceived distortions in recording were often based on differing interpretations of what 'counted' as an ABI, in the context of pressure to achieve the target.

"We have never undertook to provide an ABI and are certainly not doing it or claimed to have done it, but our screening has been interpreted as delivering an ABI" Interview number and setting withheld.

Overall, the target was viewed as a 'double-edged sword' (Interview 7) by some interviewees: important for implementation but creating perverse incentives to maximise reporting of ABI delivery.

\section{Leadership for implementation}

The identification of appropriately senior individuals to lead the implementation process and the support of other senior practitioners and staff from the start of the process, were considered crucial.

In hindsight if I was running this project again, I would have held that [first] meeting with very senior leads so hospital managers and senior medical leads. I would have rubber-stamped the initiative from very, very high up and I think that might have made things a wee [colloquial term meaning small] bit faster perhaps. Interview 7, A\&E

It was almost universally reported that the process of gaining such senior support was not easy.

It was very difficult to find a lead, a champion, someone who could grasp and lead it for the department.

Interview 1, Both settings

Some senior staff were unconvinced of the merits of delivering ABIs in the A\&E setting for evidence or appropriateness reasons.
"One of the concerns is that there's not actually from our reading of it a strong evidence base for them actually being useful in terms of outcome. There's a meta-analysis that [a colleague] gave to me [which] suggested that at best there was impact for 3 or possibly 6 months on individual's patterns of alcohol intake, so the bottom line is that we've never been convinced of the evidence base that it's been a useful thing to do."
Interview 11, A\&E

Where there was delay in appointing implementation leaders, or where the lines of responsibility for leading and reporting implementation were unclear, interviewees tended to report more of a struggle with the whole process. The status of the implementation leader was important in other ways too. One senior clinician noted that although he and his colleagues did not agree with $A \& E$ delivery of $\mathrm{ABI}$, they had co-operated out of respect for the implementation leader with whom they already had an excellent prior relationship.

Some interviewees felt that their efforts were undermined by their own position not being sufficiently senior.

There's a pecking order there. It's harder to move things when you've only got responsibility for your own wee team.

Interview 4, A\&E 
Many felt that the process of engaging senior staff could be helped by approaching them with an open mind and a readiness to acknowledge existing related work rather than assuming that $\mathrm{ABI}$ represented a completely new practice in that setting.

There was a bit of 'I've got the 10 commandments here, it's a really good way to live, I don't understand why you're not taking them.' If I had my time again the approach would be different. I would probably have a discussion with senior managers about how we can develop the best practice that you're delivering at the moment?'

Interview 1, Both settings

\section{Flexibility, collaboration and pragmatism in intervention design}

Approaching senior managers with an open mind also required a willingness to be flexible and pragmatic about the design of the programme, balancing what was desirable with what was possible.

A key lesson is not to be afraid to tweak the model. An $A B I$ is a structured conversation. It can be structured around other processes that might make it easier for staff to incorporate in their daily work.

Interview 3, Both settings

Interviewees noted a need to be pragmatic about what could be delivered in particular settings, particularly $\mathrm{A} \& \mathrm{E}$, and as a result used minimal screening approaches, or instigated ABIs in other parts of hospital system such as in admissions wards following treatment in A\&E.

\section{We started off with the full FAST screening tool completed on every patient but it was too cumbersome, but now we've just gone for the first question and if yes then a conversation about alcohol would be helpful. \\ Interview 7, A\&E}

In antenatal settings, flexibility was felt particularly important in relation to deciding how to screen women by adapting existing forms or processes, 'not to invent extra work' (interview 9) and using appropriate language that 'conforms to the language that our midwives would use' (interview 8).

The process of adaptation was helped by close working relationships with frontline staff as outlined below and a good understanding of current practice. For example, many noted that staff were already asking patients questions about alcohol in both antenatal and $A \& E$ settings. Implementation leaders used this knowledge as a starting point for $\mathrm{ABI}$ design or to support efforts to 'win hearts and minds' (interview 14) over to the feasibility and value of ABIs. Some argued that ABIs were already happening but without staff getting credit for their efforts, in an attempt to motivate staff to record and report such delivery.

\section{Recording, monitoring and reporting}

Many interviewees advised that the establishment of practical and robust recording, monitoring and reporting procedures was essential, and that it needed to happen earlier in the implementation process than had occurred. It was suggested that this should have been considered nationally rather than being the responsibility of each health board.

Unless you can capture delivery then you can't report it or know about impact. Unless you've got recording in place, you can train until the cows come home but you can't evidence it.

Interview 10, Both

The ability to provide feedback on delivery figures over time was considered by some to be a crucial tool in the implementation effort.

We monitored delivery really closely, month to month, and reported back. So if there was a dip one month... when we reported back to the setting, sometimes we would be told that it 'just slipped off the agenda' and that they would get back onto it.

Interview 2, Both

Others cited the value of comparative data:

If we had robust recording systems then I could say we're giving you reliable information month by month and...I can see exactly who's not delivering ABIs...it's a name and shame game and that's what you need before anybody is going to buy into it. People say they're having these conversations now but there's no evidence for me to go back and say they're actually delivering the ABIs.

Interviewee code withheld

This last comment illustrates the fact that in a number of boards, they had not succeeded in putting in place robust recording systems. This was found to be difficult by many interviewees in all settings. In hospital settings, there were multiple points in the care pathway where the $\mathrm{ABI}$ process could be initiated or delivered and thus 
different electronic data capture points potentially operative, and needing to be linked.

There are four, five, six different systems depending on how patients come in and progress through the NHS system...You cannot expect that because it's easy to implement a recording and information collection system in one area that it will be easy in another or that you would ask the same people about it. Interview 1, Both

Secondly, changing these systems was expensive and generated frustration, partly due to this complexity.

We're still in the process of agreeing who has access to [the recording screens] because everybody has access to different levels of the system. So that makes it really difficult trying to negotiate. It shouldn't be difficult it should be dead easy. You should be able to say every nurse and doctor in AEE should have access to that screen but for some reason it's not easy. That's the biggest bane of my life, that's not easy.

Interviewee code withheld

Finally, many interviewees reported that it was necessary for recording to be made mandatory or staff simply bypassed the electronic fields.

When the [IT system] was modified to create the mandatory field, it meant that you couldn't discharge a patient until you clicked either 'BI delivered yes/no' and that was the only thing that significantly increased the recording and now we are well in target. Interview 7, A\&E

\section{Engaging and supporting frontline staff}

Interviewees emphasised the need to work closely with frontline practitioners during the design, training and implementation stages. The need to ensure that the intervention fitted in with routine practice required input from practitioners.

Staff were very involved in all decision-making... frontline staff are the best people to tell you what's going to work and not going to work and that got us a better 'buy in' because I think staff felt that they were part of it.

Interview 3, Both settings

Implementers had to be highly flexible in how they made training available to staff, adapting national training materials to their local context and using them to deliver short courses which staff could realistically attend [3]. The need for flexibility was particularly extreme in the A\&E setting and involved trainers coming in very early in the morning, during night shifts, using online learning modules, and/or delivering one to one training on wards. This was very timeconsuming.

We broke [the training] down into bite sizes of one and a half hours... I came in very early so that I could catch the staff starting when they were at their quietest period in the emergency department and each member of staff attended three sessions of one and a half hours. This carried on for ages until everyone was trained - death by a thousand cuts.

Interview 7, A\&E

Many interviewees spoke about the importance of having working relationships on the ground with frontline staff as early as possible in the implementation effort. Indeed those health boards who had implemented $A B I$ delivery projects prior to the announcement of national target were felt to have made much more rapid progress in part because of relationships which were already in place. The role of alcohol liaison or specialist nurses (ALNs) was also seen as helpful in hospitals, both in acting as champions for delivery and supporting staff at the point of $\mathrm{ABI}$ delivery.

\section{I think some of it is about having a closer working relationship with midwives and being more of a presence and support to them. At the moment we are not in and around antenatal wards on a weekly or daily basis. We deliver training and they are on their own. Alcohol Liaison Nurses could offer advice and support to staff with management issues for people at higher risk. Interview 3, Both settings}

But while seen as desirable by some, this model was not always enough to secure delivery by frontline staff, and having a specialist in the department was reported by others as a way for staff to avoid taking on this role.

Across the hospital because of the ALNs work, some people know a bit about [alcohol], but the only people having conversations about alcohol [with patients] are the ALNS.

Interview 2, Both settings

Part of [the alcohol nurse] role was to involve other staff in what she was doing and to show them how easy it was to do but it probably wasn't successful in terms of embedding anything into practice because it gave them a get-out. Interviewee code withheld 


\section{Discussion}

Even with significant national support via a specific delivery target and additional funding, the implementation of alcohol brief interventions in settings outside of primary care proved challenging. The challenges related to competing pressures on staff and the extensive time required to restructure services, train staff in support of the initiative, motivate them to deliver in routine practice, and adapt systems for recording delivery. While implementation leaders identified five broad areas in which to focus implementation efforts, it did not necessarily follow that the implementation strategies they identified as helpful could be successfully employed, and even then implementation was highly time-consuming, and more complex than expected.

Intensive and wide-ranging implementation efforts have previously been found necessary in efforts to systematically change practice in relation to high profile issues in patient care, for example, hand hygiene [39] and HIV testing [40]. In the ABI field, some studies have identified similar themes including support from senior staff [41-44], adapting the intervention to suit current practice $[41,43,45,46]$, and establishing an effective IT system for recording and feedback $[43,45]$. Others have noted the inadequacy of training to have been a barrier to delivery $[41,45,47,48]$ and advocated a flexible approach similar to that reported by some interviewees in this study.

Much of the literature in this field highlights barriers and facilitators to implementation operating at individual practitioner level such as attitudes or skills or concerns about patient responses to ABIs [49-52]. These factors can be addressed directly [53] but were not explicitly targeted by implementation leaders in this study apart from via practitioner training, perhaps because there was in effect a requirement for ABI delivery. The approaches to implementation identified here as helpful such as targets and senior management support, tended to operate at a system or higher level unlike the factors described in one narrative review of implementation in primary care [27]. A CFIR-informed review also suggested that strategic and organisational factors as well as the process of implementation (rather than practitioner or intervention factors) could be more important for success [54].

The existence of the target for delivery of ABIs was thought to be useful by interviewees, over and above the resources that accompanied it. This kind of top-down performance management in the NHS can generate pressure on staff, focus attention on specific issues rather than holistic care, and may not always result in the intended change [55-57]. Similar concerns arose in this study; nevertheless, the few reports of distortions in the reported $A B I$ figures seem to result from two main issues: firstly, a sense that the programme merely recorded rather than changed prior practice; and secondly conflicting views of what constitutes an ABI and 'should' therefore 'count' towards the target. The target was seen by interviewees as helpful on balance, though this finding has arisen in the specific context of Scotland's national policy approach to addressing alcohol-related harm.

The need to adapt the intervention to fit with current practice in each setting in order to make it easier and more acceptable to implement, was also highlighted as important in the Swedish national 'risk drinking project [33]. However, it carries a risk of compromising the effectiveness of the intervention in ways that are currently unknown, due to the limited extent of rigorous effectiveness study in this area, and this was reflected in the uncertainty of interviewees as to what actually constituted an ABI. Interventions in the substance misuse field need to be clearer about core and adaptable components [58], and the lack of study of the required content of $\mathrm{ABI}$ for efficacious and effective delivery is a recognised weakness of the existing literature $[3,59,60]$.

The absence of a preparation period prior to the national roll-out of the target did not allow for development or intensive piloting of interventions. Given the weaknesses in the evidence base for ABIs, and the level of resourcing of the national programme, it could be seen as a missed opportunity that evaluation of the initiative did not include effectiveness studies [30]. The lack of both stronger evidence of ABI effectiveness in settings outside of primary care and earlier piloting and practical adjustments to ABIs including recording systems and associated training specific to each setting, was problematic for implementation in some areas in this study. Addressing these issues should be expected to be helpful for gaining the support of senior staff in similar initiatives in future [61].

This study captured the views of very experienced ABI implementation leaders involved in a uniquely high-profile and ambitious national implementation programme. Their reports are specific to this context in Scotland, and may not be transferable to other areas. The retrospective qualitative approach taken could not provide empirical evidence for the implementation strategies advocated by interviewees. A greater sample size may also have enabled a more in-depth comparison between different settings and perspectives, and may have enabled data saturation to be achieved. Interviewees varied however, in terms of setting, role and the size and demography of their health board area. As such their accounts are striking in their similarity, more so than in their diversity. Eight of the 14 had experience of implementation in more than one setting, making them well placed to suggest what might be important across settings. The identified factors affecting implementation also fit well however with issues known to 
be important in implementation efforts more broadly as represented in the CFIR [25]. Future national or large-scale ABI programmes could be utilised as opportunities to explore the importance of the five strategies identified here and identify other useful strategies, notwithstanding the perhaps more urgent need for further research into efficacy, effectiveness and intervention design $[59,60]$.

\section{Conclusions}

The participants in this study were responsible for the delivery of a high profile national programme that was supported by considerable resources and funding. The implementation of the programme proved complex and challenging in many respects. These implementation leaders did not benefit from prior knowledge of, or training in, implementation science. The learning reported by them was therefore in many cases gained 'the hard way' through trial and error, when many issues could have been anticipated in advance. This interview study emphasises the magnitude of the challenges involved in large scale ABI implementation efforts, as well as identifying useful learning from implementation leaders.

\section{Abbreviations}

ABI: Alcohol brief intervention; A\&E: Accident and emergency;

CFIR: Consolidated framework for implementation research.

\section{Competing interests}

JM and LP declare no competing interests. NF was the owner (until March 2014) of Create Consultancy Ltd. (CCL), a private company, commissioned by NHS Health Scotland between 2008 and 2010 to write and deliver the national training programme and associated support for the national rollout of alcohol brief interventions in Scotland which is the subject of this study. She declares that she has no other competing interests. SH was employed by CCL from 2008 to 2013 and has no other competing interests.

\section{Authors' contributions \\ $N F, L P$ and JM formulated the aims and methods of this study. NF devised the sampling strategy, conducted all interviews, conducted analysis and drafted the manuscript under the supervision of JM. SH supported analysis and interpretation of findings. JM and LP assisted with interpretations of the findings and revised drafts of the manuscript. Any potential issues concerning the dual role of NF \& SH (see competing interests) were discussed with JM throughout the conduct of this study. NF drafted the final manuscript. All authors read and approved the final manuscript.}

\section{Acknowledgements}

We would like to thank all the participants in this study and their managers and support staff who facilitated the conduct of the research.

\section{Funding}

This work was supported by funding from Islington Borough Council. Funders had no role in the design, collection, analysis, and interpretation of data; in the writing of the manuscript; or in the decision to submit the manuscript for publication. The article processing charge was funded by the University of Stirling.

\section{Author details}

'Institute for Social Marketing, UK Centre for Tobacco and Alcohol Studies, University of Stirling, Stirling FK9 4LA, Scotland, UK. ${ }^{2}$ Institute for Health and Wellbeing Research, Robert Gordon University, Riverside Campus, Aberdeen AB10 7GJ, UK. ${ }^{3}$ Faculty of Public Health and Policy, London School of
Hygiene and Tropical Medicine, 15-17 Tavistock Place, London WC1H 9SH, UK. ${ }^{4}$ Glasgow City Community Health Partnership, North-East Sector, Eastbank Health Promotion \& Training Centre, Academy Street, Glasgow G32 9AA, UK.

Received: 1 October 2014 Accepted: 12 February 2015 Published online: 25 March 2015

\section{References}

1. Heather $N$. Interpreting the evidence on brief interventions for excessive drinkers: the need for caution. Alcohol Alcohol. 1995;30:287-96.

2. McCambridge J, Cunningham $\mathrm{J}$ a. The early history of ideas on brief interventions for alcohol. Addiction. 2014;109:538-46.

3. McCambridge J. Brief intervention content matters. Drug Alcohol Rev. 2013;32:339-41.

4. Michie S, Whittington C, Hamoudi Z, Zarnani F, Tober G, West R. Identification of behaviour change techniques to reduce excessive alcohol consumption. Addiction. 2012;107:1431-40.

5. Scottish Government Health Department. HEAT (H4) Alcohol Brief Interventions - National Guidance on Data Reporting 2008-9. 2008

6. Babor TF, Higgins-Biddle JC. Brief Intervention for Hazardous and Harmful Drinking. A Manual for Use in Primary Care. Geneva: World Health Organisation; 2001

7. Kaner E, Dickinson H, Beyer F, Campbell F, Schlesinger F, Heather N, Saunders J, Burnand B, Pienaar E. Effectiveness of brief alcohol interventions in primary care (review). Cochrane Database Syst Rev 2007: Art. No.: CD004148. DOI: $10.1002 / 14651858 . C D 004148$.

8. Bertholet N, Daeppen J-B, Wietlisbach V, Fleming M, Burnand B. Reduction of alcohol consumption by brief alcohol intervention in primary care: systematic review and meta-analysis. Arch Intern Med. 2005;165:986-95.

9. Havard A, Shakeshaft A, Sanson-Fisher R. Systematic review and meta-analyses of strategies targeting alcohol problems in emergency departments: interventions reduce alcohol-related injuries. Addiction. 2008;103:368-76. discussion 377-8.

10. Nilsen P, Baird J, Mello MJ, Nirenberg T, Woolard R, Bendtsen P, et al. A systematic review of emergency care brief alcohol interventions for injury patients. J Subst Abuse Treat. 2008;35:184-201.

11. McQueen J, Howe TE, Allan L, Mains D, Hardy V. Brief interventions for heavy alcohol users admitted to general hospital wards. Cochrane database Syst Rev. 2011;8:CD005191.

12. Stade B, Bailey C, Dzendoletas D, Sgro M, Dowswell T, Bennett D. Psychological and/or Educational Interventions for Reducing Alcohol Consumption in Pregnant Women and Women Planning Pregnancy (Review). 2009:CD004228. doi:10.1002/14651858.CD004228.pub2.

13. Gilinsky A, Swanson V, Power K. Interventions delivered during antenatal care to reduce alcohol consumption during pregnancy: A systematic review. Addict Res Theory. 2011;19:235-50.

14. Dhital R, Norman I, Whittlesea C, McCambridge J. Effectiveness of alcohol brief intervention delivered by community pharmacists: study protocol of a two-arm randomised controlled trial. BMC Public Health. 2013;13:152.

15. Patton R, Deluca P, Kaner E, Newbury-Birch D, Phillips T, Drummond C. Alcohol Screening and Brief Intervention for Adolescents: The How, What and Where of Reducing Alcohol Consumption and Related Harm Among Young People. Alcohol Alcohol. 2013;0:1-6.

16. Coulton S, Newbury-Birch D, Cassidy P, Dale V, Deluca P, Gilvarry E, et al. Screening for alcohol use in criminal justice settings: an exploratory study. Alcohol Alcohol. 2012;47:423-7.

17. Pilowsky DJ, Wu L-T. Screening instruments for substance use and brief interventions targeting adolescents in primary care: a literature review. Addict Behav. 2013;38:2146-53.

18. Beich $A$, Thorsen $T$, Rollnick S. Screening in brief intervention trials targeting excessive drinkers in general practice: systematic review and meta-analysis. BMJ. 2003;327:536-42.

19. Göransson M, Magnusson A, Heilig M. Identifying hazardous alcohol consumption during pregnancy: implementing a research-based model in real life. Acta Obstet Gynecol Scand. 2006;85:657-62.

20. Sise MJ, Sise CB, Kelley DM, Simmons CW, Kelso DJ. Implementing screening, brief intervention, and referral for alcohol and drug use: the trauma service perspective. J Trauma. 2005;59(3 Suppl):S112-8. discussion S124-33. 
21. Heather N, Dallolio E, Hutchings D, Kaner E, White M. Implementing routine screening and brief alcohol intervention in primary health care: A Delphi survey of expert opinion. J Subst Use. 2004;9:68-85

22. National Institute for Health and Care Excellence. Alcohol-Use Disorders: Preventing Harmful Drinking, NICE Public Health Guidance 24. 2010 (June).

23. Scottish Government. HEAT Standard. Alcohol Brief Interventions National Guidance: 2013-14. 2013(January):1-14.

24. Government S. Changing Scotland's Relationship with Alcohol: A Framework for Action. Edinburgh: Scottish Government; 2010.

25. Damschroder L, Aron D, Keith R. Fostering implementation of health services research findings into practice: a consolidated framework for advancing implementation science. Implement Sci. 2009;15:1-15.

26. Feldstein AC, Glasgow RE. A Practical, Robust Implementation and Sustainability Model (PRISM) for Integrating Research Findings into Practice. Jt Comm J Qual Patient Saf. 2008;34:228-43.

27. Nilsen P, Aalto M, Bendtsen P, Seppä K. Effectiveness of strategies to implement brief alcohol intervention in primary healthcare. A systematic review. Scand J Prim Health Care. 2006;24:5-15.

28. Johnson M, Jackson R, Guillaume L, Meier P, Goyder E. Barriers and facilitators to implementing screening and brief intervention for alcohol misuse: a systematic review of qualitative evidence. J Public Health (Bangkok). 2010;33:412-21.

29. Scottish Government. Chief Executive's Letter, December 2007. Guidance on HEAT Targets for NHS Boards. 2007.

30. Parkes T, Atherton I, Evans J, Gloyn S, Mcghee S, Stoddart B, et al. An evaluation to assess the implementation of NHS delivered Alcohol Brief Interventions. 2011.

31. Fitzgerald N, Winterbottom J. Alcohol Brief Interventions Training Manual. Edinburgh: NHS Health Scotland; 2009.

32. Scottish Government. Changing Scotland's Relationship with Alcohol: A Discussion Paper on Our Strategic Approach. Edinburgh: Scottish Government; 2008

33. Nilsen P, Wåhlin S, Heather N. Implementing brief interventions in health care: lessons learned from the Swedish Risk Drinking Project. Int J Environ Res Public Health. 2011;8:3609-27.

34. Mäkelä P, Havio M, Seppä K. Alcohol-related discussions in health care-a population view. Addiction. 2011;106:1239-48.

35. Nilsen P, McCambridge J, Karlsson N, Bendtsen P. Brief interventions in routine health care: a population-based study of conversations about alcohol in Sweden. Addiction. 2011;106:1748-56.

36. ISD Scotland. Publication Report Alcohol Brief Interventions 2013/14. 2014. (June).

37. ISD Scotland. Alcohol Brief Interventions 2012/13. 2013(June).

38. Gale NK, Heath G, Cameron E, Rashid S, Redwood S. Using the framework method for the analysis of qualitative data in multi-disciplinary health research. BMC Med Res Methodol. 2013;13:117.

39. Huis A, van Achterberg T, de Bruin M, Grol R, Schoonhoven L, Hulscher M. A systematic review of hand hygiene improvement strategies: a behavioural approach. Implement Sci. 2012;7:92.

40. Goetz MB, Bowman C, Hoang T, Anaya H, Osborn T, Gifford AL, et al. Implementing and evaluating a regional strategy to improve testing rates in VA patients at risk for HIV, utilizing the QUERI process as a guiding framework: QUERI Series. Implement Sci. 2008:3:16.

41. Désy PM, Perhats C. Alcohol Screening, Brief Intervention, and Referral in the Emergency Department: An Implementation Study, vol. 34. 2008. p. 11-9.

42. Mcmanus S, Hipkins J, Haddad P, Guthrie E, Creed F. Implementing an effective intervention for problem drinkers on medical wards. Gen Hosp Psychiatry. 2003;25:332-7

43. Johnson JA, Woychek A, Vaughan D, Seale JP. Screening for at-risk alcohol use and drug use in an emergency department: integration of screening questions into electronic triage forms achieves high screening rates. Ann Emerg Med. 2013;62:262-6.

44. Weiland TJ, Dent AW, Phillips GA, Lee NK. Emergency clinician-delivered screening and intervention for high-risk alcohol use: a qualitative analysis. Emerg Med Australas. 2008;20:129-35.

45. Kennedy C, Finkelstein N, Hutchins E, Mahoney J. Improving Screening for Alcohol Use During Pregnancy: The Massachusetts ASAP Program. Matern Child Health J. 2004:8:137-47.

46. Fitzgerald N, Molloy H, MacDonald F, McCambridge J. Alcohol brief interventions practice following training for multidisciplinary health and socia care teams: a qualitative interview study. Drug Alcohol Rev. 2015;34(2):185-93.
47. Brooker C, Peters J, McCabe C, Short N. The views of nurses to the conduct of a randomised controlled trial of problem drinkers in an accident and emergency department. Int J Nurs Stud. 1999;36:33-9.

48. Li C, Olsen Y, Kvigne V, Welty T. Implementation of substance use screening in prenatal clinics. S D J Med. 1999;52:59-64

49. Anderson S, Eadie DR, MacKintosh AM, Haw S. Management of alcohol misuse in Scotland: the role of A\&E nurses. Accid Emerg Nurs. 2001;9:92-100.

50. Graham DM, Maio RF, Blow FC, Hill EM. Emergency physician attitudes concerning intervention for alcohol abuse/dependence delivered in the emergency department: a brief report. J Addict Dis. 2000;19:45-53.

51. Doi LK. Screening and alcohol brief interventions in antenatal care: a realistic evaluation. University of Stirling; 2012. http://dspace.stir.ac.uk/ handle/1893/9513.

52. Duncan EM. Alcohol and nicotine use during pregnancy: it's nature, occurrence and consequences. Robert Gordon University; 2010. https:// openair.rgu.ac.uk/bitstream/10059/661/1/Eilidh\%20Duncan\%20PhD.pdf.

53. McCambridge J, Platts S, Whooley D, Strang J. Encouraging Gp Alcohol Intervention: Pilot Study of Change-Orientated Reflective Listening (Corl). Alcohol Alcohol. 2004:39:146-9.

54. Williams EC, Johnson ML, Lapham GT, Caldeiro RM, Chew L, Fletcher GS, et al. Strategies to implement alcohol screening and brief intervention in primary care settings: a structured literature review. Psychol Addict Behav. 2011;25:206-14.

55. Bevan G. Setting Targets for Health Care Performance: Lessons from a Case Study of the English NHS. Natl Inst Econ Rev. 2006;197:67-79.

56. Gubb J. Have targets done more harm than good in the English NHS? Yes. BMJ. 2009;338:a3130.

57. Bevan G. Have targets done more harm than good in the English NHS? No. BMJ. 2009;338:a3129.

58. Damschroder L, Hagedorn H. A guiding framework and approach for implementation research in substance use disorders treatment. Psychol Addict Behav. 2011;25:194-205.

59. Gaume J, McCambridge J, Bertholet N, Daeppen J-B. Mechanisms of action of brief alcohol interventions remain largely unknown - a narrative review. Front Psychiatry. 2014;5:108.

60. Heather $\mathrm{N}$. The efficacy-effectiveness distinction in trials of alcohol brief intervention. Addict Sci Clin Pract. 2014;9:13.

61. McCambridge J. Fifty years of brief intervention effectiveness trials for heavy drinkers. Drug Alcohol Rev. 2011;30:567-8.

62. Tong A, Sainsbury P, Craig J. Consolidated criteria for reporting qualitative research (COREQ): a 32-item checklist for interviews and focus groups. Int J Qual Health Care. 2007;19:349-57.

63. Clark J. How to peer review a qualitative manuscript. In: Godlee F, Jefferson T, editors. Peer Rev Heal Sci. Second. London: BMJ Books; 2003. p. 219-35.

\section{Submit your next manuscript to BioMed Central and take full advantage of:}

- Convenient online submission

- Thorough peer review

- No space constraints or color figure charges

- Immediate publication on acceptance

- Inclusion in PubMed, CAS, Scopus and Google Scholar

- Research which is freely available for redistribution 